\title{
Alveolar rhabdomyosarcoma presenting as subacute intravascular coagulation
}

\author{
A. ELDOR, ELLA NAPARSTEK, 1 J. H. BOSS, ${ }^{2}$ AND SHOSHANA BIRAN 3
}

From the Departments of Haematology, ${ }^{1}$ Pathology, ${ }^{2}$ and Oncology, ${ }^{3}$ Hadassah Medical Organization, Jerusalem, Israel

SUMmARY A patient with rhabdomyosarcoma is described in whom the presenting clinical and laboratory features were those of disseminated intravascular coagulation. The patient's rapid downhill course was primarily expressed by haemorrhagic tendency. An alveolar rhabdomyosarcoma, affecting many organs, including vascular and cardiac lumina, was found at necropsy and was considered to be the cause of the consumption coagulopathy.

Rhabdomyosarcoma, the malignant tumour of striated muscle, is one of the more common soft tissue tumours. Horn and Enterline (1958) subdivided this neoplasm into the pleomorphic botryoid, embryonal, and alveolar varieties. The alveolar rhabdomyosarcoma occurs mainly in young persons (Enzinger and Shiraki, 1969). The prognosis is poor and the median survival about eight months. The cause of death in most patients is haematogenous and lymphatic metastatic spread. To the best of our knowledge, haemorrhagic tendency has been described in only three cases of alveolar rhabdomyosarcoma (Merskey et al., 1967; Lechner and Moran, 1952) while it has not been observed in any of the 110 cases reported by Enzinger and Shiraki (1969). We have recently treated a patient with alveolar rhabdomyosarcoma who presented with signs and symptoms of a severe bleeding tendency. The laboratory findings were compatible with the diagnosis of subacute disseminated intravascular coagulation leading to a consumption coagulopathy. Because of the rarity of this condition it seemed worthwhile to report this patient's illness.

\section{Case report}

A 44-year-old Israeli-born Caucasian engineer was admitted to the Department of Haematology of the Hadassah Hospital for evaluation on 16 June 1975.

Received for publication 13 December 1976
He complained of fatigue, weight loss, fever $\left(39^{\circ} \mathrm{C}\right)$, night sweats, and chest as well as low back pain for one month. Two weeks before admission several lumps on both sides of the neck and large subcutaneous haematomas developed. The stools had been soft and tarry black for the last few days. The patient had been in hospital elsewhere and treated with chloramphenicol and gentamicin. Since there was no improvement he was transferred to our hospital. His family and past histories were noncontributory. He appeared severely ill and pale, his temperature was $39^{\circ} \mathrm{C}$, and blood pressure $130 / 80$ $\mathrm{mmHg}$. The pulse rate was 96 per minute and regular, the respiratory rate 28 per minute. Two large subcutaneous haematomas were found on the chest and left buttock respectively. Tender lumps, measuring $2 \times 2 \mathrm{~cm}$ in diameter, adherent to the adjacent tissues, were palpated on both sides of the neck. Bronchial breathing was heard over the base of the left lung. The heart sounds were normal. The abdomen was soft and not tender. The liver was palpable $4 \mathrm{~cm}$ below the right costal margin; it was firm and not tender. The spleen was palpable. Rectal examination did not disclose any abnormality. The patient had melaena. There were no abnormalities on neurological examination.

\section{LABORATORY TESTS}

The blood sedimentation rate (Westegren examination) was $15 \mathrm{~mm}$ in the first hour. The haemoglobin was $7.9 \mathrm{~g}$. The white blood cell count was $7.7 \times 10^{9} / 1$ with a normal differential count. The number of 
platelets was $60 \times 10^{9} / 1$. Red cells were normocytic and normochromic. Blood urea nitrogen glucose and electrolytes were within the normal range. The serum uric acid was $8.4 \mathrm{mg} / \mathrm{dl}$, bilirubin $2.5 \mathrm{mg} / \mathrm{dl}$, and alkaline phosphatase $380 \mathrm{u} / \mathrm{ml}$ (normal $30-70 \mathrm{u} / \mathrm{ml}$ ). Glutamic oxaloacetic transaminase (SGOT) was $480 \mathrm{u} / \mathrm{ml}$ (normal 24-50 u/ml) and lactic dehydrogenase $(\mathrm{LDH}) 2900 \mathrm{u} / \mathrm{ml}$ (normal 150-300 u/ml). Vitamin $B_{12}$ was $4000 \mathrm{pg} / \mathrm{ml}$ (normal $200-900 \mathrm{pg} / \mathrm{ml}$ ). Electrophoresis and immunoelectrophoresis of the serum proteins were normal. The alphafetoprotein level in the serum was not raised. Blood, sputum, and urine cultures were sterile. Urine analysis disclosed a few erythrocytes in the sediment. Chest radiographs showed several small, round shadows in both lung fields. Intravenous pyelography was normal, although a big mass about $6 \times 15 \mathrm{~cm}$ in diameter, was visualised over the left psoas muscle, displacing the left kidney laterally and upwards. A liver scan showed an enlarged liver with multiple small filling defects. The patient's course was rapidly downhill. Subcutaneous haemorrhages continued to appear and melaena was observed daily. On the first day in hospital, sudden paralysis of the left recurrent laryngeal nerve, with slight hoarseness, developed. Biopsy of one of the nuchal lumps revealed an organised haematoma. The results of the coagulation studies suggested a consumption coagulopathy and are summarised in the Table. The lack

Table Coagulation studies

\begin{tabular}{|c|c|c|c|c|c|}
\hline & $\begin{array}{l}\text { June } \\
16\end{array}$ & 20 & 24 & 26 & 29 \\
\hline $\begin{array}{l}\text { Platelets } \times 10^{\circ} / 1 \\
\text { Clotting time (min) } \\
\text { (Lee and White, 1913) }\end{array}$ & $\begin{array}{r}60 \\
8\end{array}$ & $\begin{array}{r}70 \\
9\end{array}$ & $\begin{array}{r}60 \\
7\end{array}$ & $\begin{array}{r}50 \\
8\end{array}$ & 60 \\
\hline $\begin{array}{l}\text { Prothrombin time (\%) } \\
\text { (Quick, 1951) }\end{array}$ & 47 & 25 & 40 & 47 & 36 \\
\hline $\begin{array}{l}\text { Partial thromboplastin time (s) } \\
\text { (Proctor and Rapaport, 1951) }\end{array}$ & 39 & 38 & 36 & 41 & 40 \\
\hline $\begin{array}{l}\text { Fibrinogen (mg/dl) } \\
\text { (Ratnoff and Menzie, 1951) }\end{array}$ & 215 & & 174 & 69 & \\
\hline $\begin{array}{l}\text { Euglobulin lysis time-started (min) } \\
\text { (Von Kaulla and Schultz, 1958) }\end{array}$ & 105 & 70 & 90 & 45 & 90 \\
\hline $\begin{array}{l}\text { Fibrinogen related material }(\mu \mathrm{g} / \mathrm{ml}) \\
\text { (Merskey } \text { et al., 1966) }\end{array}$ & & 160 & & 320 & \\
\hline
\end{tabular}

of a histological diagnosis, notwithstanding, it was assumed that the patient was suffering from a rapidly growing malignant tumour complicated by consumption coagulopathy. The patient was treated by intravenous injections of $200 \mathrm{mg}$ cyclophosphamide daily, $250 \mathrm{mg}$ hydrocortisone acetate, and 10000 units heparin, the latter given in four divided doses. In addition, he received $300 \mathrm{mg}$ of allopurinol daily. Blood and platelet transfusions were administered frequently. No response to therapy was apparent, the patient's condition deteriorated rapidly, and deep jaundice (bilirubin $10 \mathrm{mg} / \mathrm{dl}$ ) developed. Bloody diarrhoea and haematuria were noted during the three days before death. The patient lost conscious $-\frac{\vec{F}}{\vec{c}}$ ness on the 15th day in hospital and died within a few hours.

\section{NECROPSY FINDINGS}

The body was that of a well nourished man. The peritoneal cavity contained $600 \mathrm{ml}$ of serosanguinous fluid. An elongated mass, bulging anteriorly, was $\overrightarrow{0}$ found within the left psoas muscle. Cut sections $\overrightarrow{-}$ revealed a spindle-shaped, soft, fleshy tumour mass, $\omega$ measuring $8 \times 5 \times 4 \mathrm{~cm}$, surrounded by muscle tissue on all its aspects. Although not encapsulated, the tumour was well demarcated from the adjacento muscle tissue. There was widespread metastatic $v$ spread involving the heart, larynx, trachea, lungs, $\rightarrow$ liver, spleen, lymph nodes, pancreas, omentum, 0 mesentery, parietal peritoneum, kidneys, urinary bladder, thyroid and adrenal glands, fat tissue, and ${ }_{c}$ bones. The liver $(4500 \mathrm{~g})$ and spleen $(720 \mathrm{~g})$ were studded with numerous, variously sized tumournodules, the largest being $2.5 \mathrm{~cm}$ in diameter. Central $\stackrel{\oplus}{-}$ softening and haemorrhages were found on cutting. through many of these nodules. The lungs (right? $550 \mathrm{~g}$; left $720 \mathrm{~g}$ ) contained a multitude of smalls round tumour nodules, ranging up to $0.5 \mathrm{~cm}$ in diameter, and were the site of massive intra-alveolaro haemorrhage. There were petechial haemorrhages $\triangle$ in all serosal membranes.

Histologically, the tumour of the psoas muscle 3 and the metastatic nodules showed variously sized, round, oval or polygonal nests and islands, sharplyọ. separated from each other by delicate, vascularised, connective tissue septa. In some areas, sheets and? anastomosing cords were evident. These features imparted on the neoplasm an epithelial-like appearance, which was emphasised in silver-impregnated $\frac{\mathrm{O}}{3}$ sections. While one, two, and, rarely, more layers of cells were closely attached to the septa, the vast $\mathrm{O}$ majority of the cells were separated and unattached $>$ (Fig. 1). The cells were oval, elongated, spindleshaped or strap-like; a few tennis racket-like cells ${ }_{0}$ were also found (Fig. 2). Cells abutting on the septa were cuboidal or polyhedral. Binucleated or bizarre, multinucleated giant cells were abundant. $\omega$ The cytoplasm was deeply eosinophilic, and cross? striations were not seen in sections stained withe haematoxylin and eosin or phosphotungstic acid haematoxylin. The nuclei varied in size and shape, $\stackrel{?}{+}$ most being round or ovoid and eccentrically placed; -0 eosinophilic intranuclear inclusions were frequent. $\frac{\mathrm{O}}{\mathbb{D}}$ The thyroid gland was the site of several small? metastases. One round whitish nodule, $4 \times 6 \mathrm{~mm}$ in $\varnothing$ dimension, was a highly differentiated papillary cystadenocarcinoma (Fig. 3). 


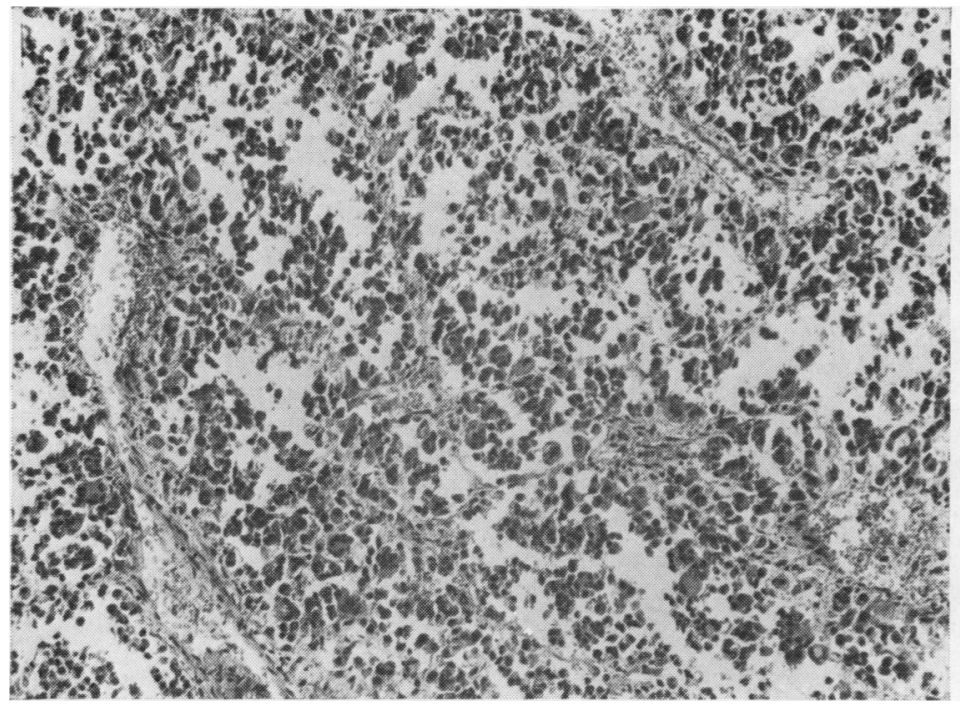

Fig. 1 General view of tumour. Most tumour cells are freely floating, the septa being lined by a layer of one to three cells thick. Haematoxylin and eosin $\times 100$.

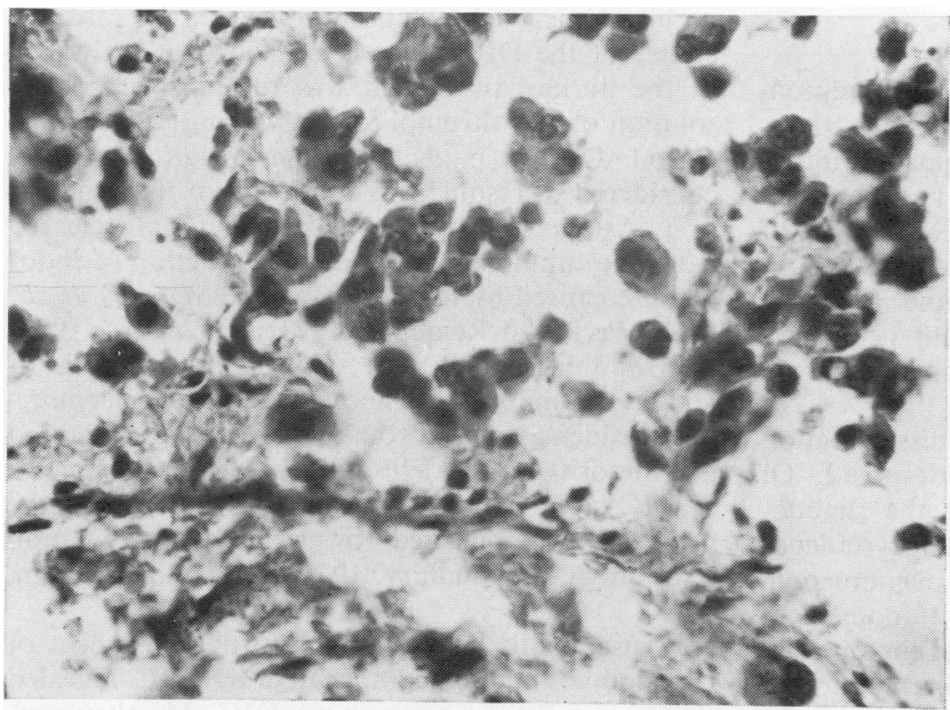

Fig. 2 Higher magnification showing the variously shaped free floating tumour cells. Other cells are attached to the septa. Note tennis racket cells. Haematoxylin and eosin $\times 420$

In addition to many pericardial and myocardial tumour nodules, there were several metastases in the endocardium, in the shape of small, round or oval foci, replacing adjacent myocardium presenting as intracavitary bosselations, some of which appeared as polypoid structures. Other pertinent findings were extramedullary haematopoiesis in the liver, spleen, and adrenal glands, jaundice and intrahepatic cholestasis, recent jejunal and ileal haemorrhages, pulmonary oedema, acute passive congestion of the internal organs, and terminal pancreatitis. Patchy intra-alveolar haemorrhages were found in both lungs. The small and medium-sized blood vessels were meticulously searched for fibrin platelet thrombi. None was found except for recent thrombi in the small veins of the tumour septa. There were tumour cell emboli in a few glomerular capillaries. A single vein contained a mural organising thrombus, in which several tumour cells were lodged. An osteoma was found in the frontal bone. The brain was oedoematous, and cut sections revealed recent intracerebellar and subarachnoid haemorrhage. 


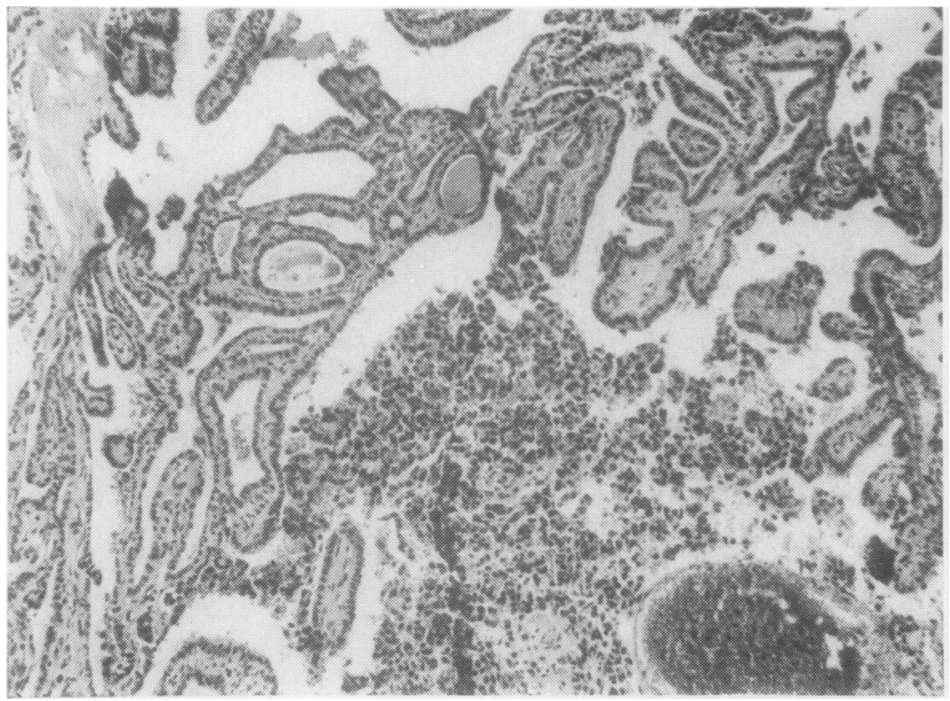

Fig. 3 Highly differentiated papillary cystadenocarcinoma of the thyroid gland containing metastatic rhabdomyosarcoma cells. Haematoxylin and eosin $\times 90$.

\section{Discussion}

The patient presented with an unusual symptom complex comprising a widely spread alveolar rhabdomyosarcoma and subacute disseminated intravascular coagulation manifested by a generalised haemorrhagic tendency. The histological features of the neoplasm are characteristic of alveolar rhabdomyosarcoma as described by Horn and Enterline (1958). This is a particularly malignant neoplasm, most affected patients dying within a short time from the onset of clinical signs.

At necropsy of our patient, tumour dissemination was found to be extensive and widespread. Of special interest are the metastases of the rhabdomyosarcoma into a low-grade papillary cystadenocarcinoma of the thyroid gland. This phenomenon, referred to as metastasis of tumour to tumour, is of extreme rarity, the more so as the host tumour was also malignant. Furthermore, dissemination to the endocardium and intracavitary growth pattern in the form of polypoid structures are also unusual.

In the last month of his life the patient suffered from a haemorrhagic tendency, associated with progressive changes of the clotting mechanism. The thrombocytopenia, decline in fibrinogen, and the high titres of fibrinogen-related material (fibrinogen degradation products) support the diagnosis of subacute disseminated intravascular coagulation (DIC). The latter was presumably triggered by the widely spread tumour metastases, which invaded blood vessels and the interior of the heart. It is not surprising that no fibrin-platelet thrombi were found on histological examination, in view of the subacute course of the DIC, since it is likely that activation of the fibrinolytic system was responsible for dissolution of any thrombi formed during the terminal period. DIC in patients with metastatic cancer is considered to result from activation of the coagulation system by thromboplastic material released from the tumour tissue and/or destruction of endothelium caused by tumour invasion (Merskey et al., 1967; Peck and Reiquam, 1973; Sun et al., 1974; Al-Mondhiry, 1975). The clinical presentation of DIC in the majority of cancer patients is a haemorrhagic tendency, while thrombotic events are evidenced in a minority only (Al-Mondhiry, 1975). Some cases of DIC complicating cancer are asymptomatic, the process being detected by impaired coagulation tests only (Al-Mondhiry, 1975; Peck and Reiquam, 1973).

Perusal of the literature for further instances of rhabdomyosarcoma complicated by DIC revealed three cases. In their report on DIC, Merskey and Johnson (1966) mentioned two such examples. The third case, reported by Lechner and Moran (1952), when the concept of DIC was not yet recognised, is that of a rhabdomyosarcoma in a patient who died of massive gastrointestinal haemorrhage. In the patient described here the causal connection between the tumour and the DIC is suggested by the lack of other possible causes such as septicaemia or shock.

\section{References}

Al-Mondhiry, H. (1975). Disseminated intravascular coagulation. Experience in a major cancer center. 
Thrombosis et Diasthesis Haemorrhagica, 34, 181-193.

Enzinger, F. M. and Shiraki, M. (1969). Alveolar rhabdomyosarcoma, an analysis of 110 cases. Cancer, 24, 18-31.

Horn, R. C., Jr. and Enterline, H. T. (1958). Rhabdomyosarcoma: a clinicopathological study and classification of 39 cases. Cancer, 11, 181-199.

Lechner, F. C., Jr. and Moran, T. J. (1952). Rhabdomyosarcoma with fatal haemorrhage from intestinal metastases: case report with autopsy. American Journal of Clinical Pathology, 22, 461-465.

Lee, R. I. and White, P. D. (1913). A clinical study of the coagulation time of blood. American Journal of Medical Science, 145, 495-503.

Merskey, C. and Johnson, A. J. (1966). Diagnosis and treatment of intravascular coagulation. Pathogenesis and treatment of thromboembolic diseases. Thrombosis et Diasthesis Haemorrhagica, Supplement 21, 555-563.

Merskey, C., Johnson, A. J., Kleiner, G. J., and Wohl, H. (1967). The defibrination syndrome: clinical features and laboratory diagnosis. British Journal of Haematology, 13, 528-549.

Merskey, C., Kleiner, G. J., and Johnson, A. J. (1966).
Quantitative estimation of split products of fibrinogen in human serum, relation to diagnosis and treatment. Blood, 28, 1-18.

Peck, S. D. and Reiquam, C. W. (1973). Disseminated intravascular coagulation in cancer patients: supportive evidence. Cancer, 31, 1114-1119.

Proctor, R. R. and Rapaport, S. I. (1961). The partial thromboplastin time with kaolin: a simple screening test for first stage plasma clotting factor deficiencies. American Journal of Clinical Pathology, 36, 212-219.

Quick, A. J. (1951). The Physiology and Pathology of Haemostasis, p. 125. Lea and Febiger, Philadelphia.

Ratnoff, O. D. and Menzie, C. (1951). A new method for the determination of fibrinogen in small samples of plasma. Journal of Laboratory and Clinical Medicine, 37, 316-320.

Sun, N. C. J., Bowie, E. J. W., Kazmier, F. J., Elveback, L. R., and Owen, C. A., Jr. (1974). Blood coagulation studies in patients with cancer. Mayo Clinic Proceedings, 49, 636-641.

Von Kaulla, K. N. and Schultz, R. L. (1958). Methods for evaluation of human fibrinolysis. American Journal of Clinical Pathology, 29, 104-112. 